\title{
Factors Influencing Rational Use Of Psychotropic Medicines In Mathari National Teaching And Referral Hospital In Nairobi, Kenya
}

\author{
Dipti Ashish Bhavsar*, Dr. Kezia Njoroge ${ }^{* *}$, Ms. Lillian Muiruri***
}

${ }^{*}$ B. Pharm

** PhD in Public Health, Msc International Health, Msc Development Economic, Bachelor of Education (ARTS) Economics and Mathematics

**** Department of Health Systems Management and Medical Education, School of Medicine and Health Sciences, Kenya Methodist University

DOI: 10.29322/IJSRP.11.08.2021.p11678

http://dx.doi.org/10.29322/IJSRP.11.08.2021.p11678

\begin{abstract}
The World Health Organization recommends a focus on the six building blocks of a health system in order to strength health systems. The focus of this study was medicines, vaccines and technologies, with rational use of medicines of the psychotropic variety being the area of interest. An equity, quality, affordability and efficiency of the health care system hinders due to inappropriate use of medicines. It is evaluated that, in lowincome and middle-income countries, $80 \%$ people with genuine mental issues do not get the treatment that they require. Lack of access to psychotropic medicine may be attributed to irrational use of these medicines and is seen to lead to inflated treatment costs, mortality, and morbidity and may be reason for undesirable drug reactions or discouraging psychosocial impact. According to the Ministry of Health, Kenya Mathari national teaching \& referral hospital is faced with non-availability of psychotropic medications already on the essential drugs list. The main aim of the study was to assess the health care provider's perspective on factors influencing rational use of psychotropic medicines in Mathari National Teaching \& Referral hospital in Nairobi, Kenya. This

$\mathrm{W}$
\end{abstract} was an institutional based cross sectional descriptive study. A target population for this study was 125 prescribers and dispensers who worked at Mathari Teaching and Referral hospital at the time of study. For the study simple random sampling was used to draw a sample size of 96 respondents. A structured five-point Likert scale questionnaire was used to collect the data; the data was analysed using SPSS version 23. Results showed that, 58 (62\%) were female, $45(49 \%)$ were $31-40$ years, $60(65 \%)$ were doctors and $47(51 \%)$ held a Bachelor's Degree, The coefficient of correlation of prescribing practices $(r=0.397, \quad p<0.001)$, patientcare factors $(r=0.289, p=0.005)$, health facility factors $(r=0.446, \quad p<0.001)$ and complementary factors $(r=0.313$, $p=0.002$ ) showed a positive and significant relationship with rational use of psychotropic medicines. In a combined relationship Prescribing factors $(p=0.006)$, Health Facility factors $(p=0.011)$ and Complementary factors $(p=0.009)$, all had a significant influence on the appropriate use of psychotropic medicines. Efforts to improve the rational drug use would call for prioritized improvement of health facility factors focusing on the supply chain, followed by prescribing factors, complementary factors and finally the patient care factors. This study recommends that: Prescribers and dispensers ought to be provided with policy guidelines for rational drug use, these are the guidelines for standard treatment and a list of essential medicines, in addition to the available medicines list. Training on the rational use of psychotropic medicines for staff needs to be undertaken frequently. In addition, new staff should undergo induction training on the rational drug use as part of the orientation process. Continuous education on use of Essential medicines should be incorporated in health training institutions /hospital. NHIF the Kenyan social health insurer ought to consider covering mental health as part of the benefit package to enhance affordability of psychiatric services.

Index Terms- Psychotropic drugs, Essential Medicine List, standard treatment guidelines ,Health system, Rational Drug use, Guidelines and policies,

\section{INTRODUCTION} Background of the Study

orld Health Organization emphasize on the six pillars of a health system in order to strengthen health systems. For the wellfunctioning health system, essential medical products, vaccines and technologies must have equitable access, safe, evidence based treatment and cost-effective appropriate use. Inappropriate use of medicines hinders an equity, quality, affordability and efficiency of the health care system. Around the world, the usage of drugs is a complicated issue. The society cannot speculate how drugs are used, the government agencies are the main bodies responsible for protecting its citizens on the way they use drugs and the type of drugs to be used (Adeponle, et al., 2017). There are many different factors that will determine the kind of prescription you will be given by your doctor. Most important medicines should be available at any time and prescribed adequately and timely, and in the exact dosage needed. The prices of the medications should and must also be affordable (World Health Organization, 2010).

According to the World Health Organisation (WHO) 2012 report, which has promoted various actions for improving medicine situations, some of which include the improvement and mandatory use of a National essential medicines list, efficient procurement and supply chain management, encouraging timely screening and correct diagnosis, assisting in the operationalization of evidence-based treatment guidelines and the rational use of medicines. When medicines are not used rationally it can lead to 
worsening of the health system inequities, compromised health of patients, loss of resources, and the health systems sustainability will be endangered (Basrowi, et al., 2018).

According to a fact sheet there are significantly higher numbers of patients that take wrongly prescribed medicines in comparison to the ones who take their rightly prescribed medicines (Abebaw, et al., 2016). A study done in a group of people with mental illness recorded that $58 \%$ of them took the recommended dosage of antipsychotic and they ranged from $25.9 \%$ to $95.9 \%$ in different nations. The group of patients that were on antidepressant $57.9 \%$ of patients took the exact dosage worldwide while in the developing nations this ranged from $39.9 \%$ to $89.9 \%$ and only slightly more than a third of the patients that are treated as per the guidelines given in their clinics (Abebaw et al., 2016).

In Countries that have low or medium income per annum, up to $67 \%$ of the expenditure for health is paid out directly by consumers without insurances covering the cost. Medicine-related waste occurs through the minimal use of non-specific products; the erratic supply of medical products in public sector health facilities; particularly among the underprivileged and for prolonged conditions, having to pay for their medicines many families have to face impoverishments (Hulka, et al., 2016).

Mental issues are responsible, worldwide for $32 \%$ of long periods of incapacity and $13 \%$ of handicap balanced life years (Kilbourne, et al., 2018). In spite of the commitment to mental health issues to the worldwide weight of sickness, the nature of care for such issues remains problematic, due to there being relentless missing steps in access to and receipt of psychiatric healthcare services around the world (Kilbourne, et al., 2018). It is evaluated that among the people living in developing nations four out of five people with genuine mental issues do not get the efficient treatment that is needed (Ministry of Health, 2015).

In many Low \& Middle income Nations, there are issues when it comes to helping the patients with health issues since their facilities are not well equipped (WHO, 2017a). In Kenya, the government's total expenditure on mental health was $0.01 \%$ of total government expenditure for healthcare (WHO, 2017b). In Kenya the frequency of psychological well-being, neurological, and substance use is evaluated to be up to a quarter of the outpatients and up to two-fifths of in-patients in health facilities experience various sorts of psychiatric diseases (Ministry of Health Kenya, 2015).

In order to advance the overall drug use, and to know the shortcomings in the appropriate use of medicines; International agencies like World Health Organization (WHO) and International Network for Rational Use of Drugs (INRUD) have suggested the standard drug use pointers (Alam, et al., 2016). There are numerous variables that add to the normal medication use, including exuding from understanding (Adherence), prescribers, work environment (wellbeing framework), supply chain (product selection, procurement, and health finance), policy guidelines, drug information or misinformation, or a blend of these elements (Richard and Akosua, 2016). Adherence to medication, as incorrect use either overuse or under use, is a key issue from a patients point of view; patients' information on the right dose; patients with psychological sickness often do not take the recommended portion of the endorsed amount of medications because of numerous reasons (Padmanathan \& Rai, 2016). The accessibility of medications is critical to evaluate the nature of utilization, for example, suitable prescription practice, and sensible medication use and client adherence.

By evaluating the pattern of use of medication in a health facility, it is possible to distinguish the medication use issue and consequently to advance sound medication use and help strategy producers to execute arrangements on rational use of drug practice in the institute. The point of this study was to assess the health care provider's perspective on factors influencing rational use of psychotropic medication in the Mathari National Teaching \& Referral Hospital.

\section{Statement of Problem}

Irrational prescribing practice of drugs can adversely affect the health service delivery, access to essential medicine, Governance \& Policies and health finance (MSH, 2012b). Nonetheless, the World Health Organization reports reveals that over half of all the drugs are not effectively prescribed or dispensed, and over $50 \%$ of patients do not take their medicines accurately (Abebaw, et al., 2016). Mathari National Teaching \& Referral Hospital has been faced with various challenges that hinder effective delivery of mental health services including rational prescription of medication. According to the Ministry of Health (2020) Mathari hospital is faced with non-availability of psychotropic medications already on the essential drugs list. Access to mental healthcare in Kenya is inadequate, inefficient and inequitable, with an $85 \%$ estimated treatment gap in mental healthcare system (Marangu, et al., 2014). A study shows that in average, medicines in private facilities are available $66 \%$ of the time and $35 \%$ in public facilities in low-income and middleincome nations. A research led by Nyabuti et al., (2020) reveals in Kenya medicines prescribed by generic name were $27.7 \%$, from $76.3 \%$ medicines dispensed to the patients, only $20 \%$ prescribers used copy of Kenya essential medicine list, $80 \%$ essential medicines from Kenya Essential Medicine List were available, $54.7 \%$ patients had knowledge on medicine use; and $22.6 \%$ of drugs properly labelled. According to the Kenya Mental Health Taskforce report of 2020, $0.01 \%$ of the national health budget is allocated to mental health. The amount of money that ought to be spent on mental health is KES 250 per capita but Kenya is spending only 15 cents. The NHIF cover is not comprehensive and private insurance policies are discriminatory, as a result, Kenyans have to use their own financial resources for mental healthcare (MOH ,2020). There is scant data and information on the prevalence of neuropsychiatric diseases in Kenya. This study seeks to assess the health care provider's perspective on factors influencing rational use of psychotropic medicine at the Mathari National Teaching \& referral Hospital.

\section{REVIEW OF RELATED LITERATURE}

\section{Introduction}

This publication is licensed under Creative Commons Attribution CC BY

http://dx.doi.org/10.29322/IJSRP.11.08.2021.p11678 
The focus of this chapter is to review literature related to the factors influencing rational use of psychotropic medicines. It will identify the inappropriate use of resources, inappropriate use of medicines which affects patients' confidence in the mental health system.

\section{Theoretical Framework}

\section{Theory of Reasoned Action (TRA)}

The Theory of reasoned action (TRA) was reviewed by Ajzen (2012). It is comprised of three develops in particular conduct aim, demeanour and abstract standard. The hypothesis recommends that a person's conduct goal is an element of the person's mentality about the conduct and abstract standards. Social aim characterized as the person's general quality of aim to play out a conduct. Mentality involves the different convictions about the results of playing out the conduct duplicated by the appraisals of these results. Emotional standard involves the apparent desires from the people and the goals to agree to these desires. As indicated by TRA, individuals build up specific convictions or regularizing convictions concerning whether certain practices are adequate (Ajzen, 2012).

These convictions shape one's view of the conduct and decide one's goal to perform or not play out the conduct. To put it plainly, a person's volitional (deliberate) conduct is anticipated by the mentality toward the conduct being referred to and how it is accepted that others would see them if the conduct is performed. For instance, on account of determining medication use, on the off chance that one accepts that the utilization of a medication (the conduct) is acknowledged as accommodating inside one's social gathering, one will more probable utilize the medication. Then again, if one's companion's bunches see that the conduct isn't useful, one will be more averse to take part in the medication use.

\section{The Theory of Planned Behaviour (TPB)}

The Theory of planned behaviour (TPB) was made to speak to the inadequacy in the TRA with the extension of the Theory of planned behaviour (PBC) create (Notani, 2005). Plan Behaviour is described by Ajzen and Fishbein (1980) as a person's feelings concerning how basic or irksome execution of the lead is most likely going to be. Feelings about resources and openings are often observed as fundamental factors influencing Plan behaviour. Thusly, similarly as having elevating points of view toward purchasing a thing and having social inspirations to do in that capacity, PBC should have the choice to besides predict desires for purposefully purchasing drugs reliant on the clear straightforwardness or inconvenience related with this lead. In case an individual sees the individual has order over performing conduct, the individual will undoubtedly outline strong objectives to play out the lead and the reverse way around (Armitage \& Conner, 2003). The hypothesis of arranged conduct is one of the most generally applied hypothetical models and has been seen as powerful in foreseeing a scope of wellbeing expectations and practices including drug use (Hagger \& Chatzisarantis, 2014). It has been valuable in understanding a scope of adherence practices remembering prescription adherence for an assortment of conditions. This hypothesis is significant in long haul expectation of conduct adherence in sedate use. This is significant with regards to utilizing the hypothesis as a reason for mediations to change conduct as it will help recognize the most feasible objective builds for intercessions to elevate social adherence to sane medication use. This is on the grounds that the outcomes of non-adherence to balanced medication use are normally more genuine than not undertaking a wellbeing conduct to assist by and large wellbeing, as the illness or side effects may fall apart quickly if an individual doesn't hold fast to the treatment or prescription. This Theory is among the most appropriate and frequently considered analytical tool theories when to predict the prescribing practice within the context of health care. The factors are marketing factors, patients characteristic, pharmacist factor, some of them are reflected in my research questions (Ali Murshid \& Mohaidin, 2017). 


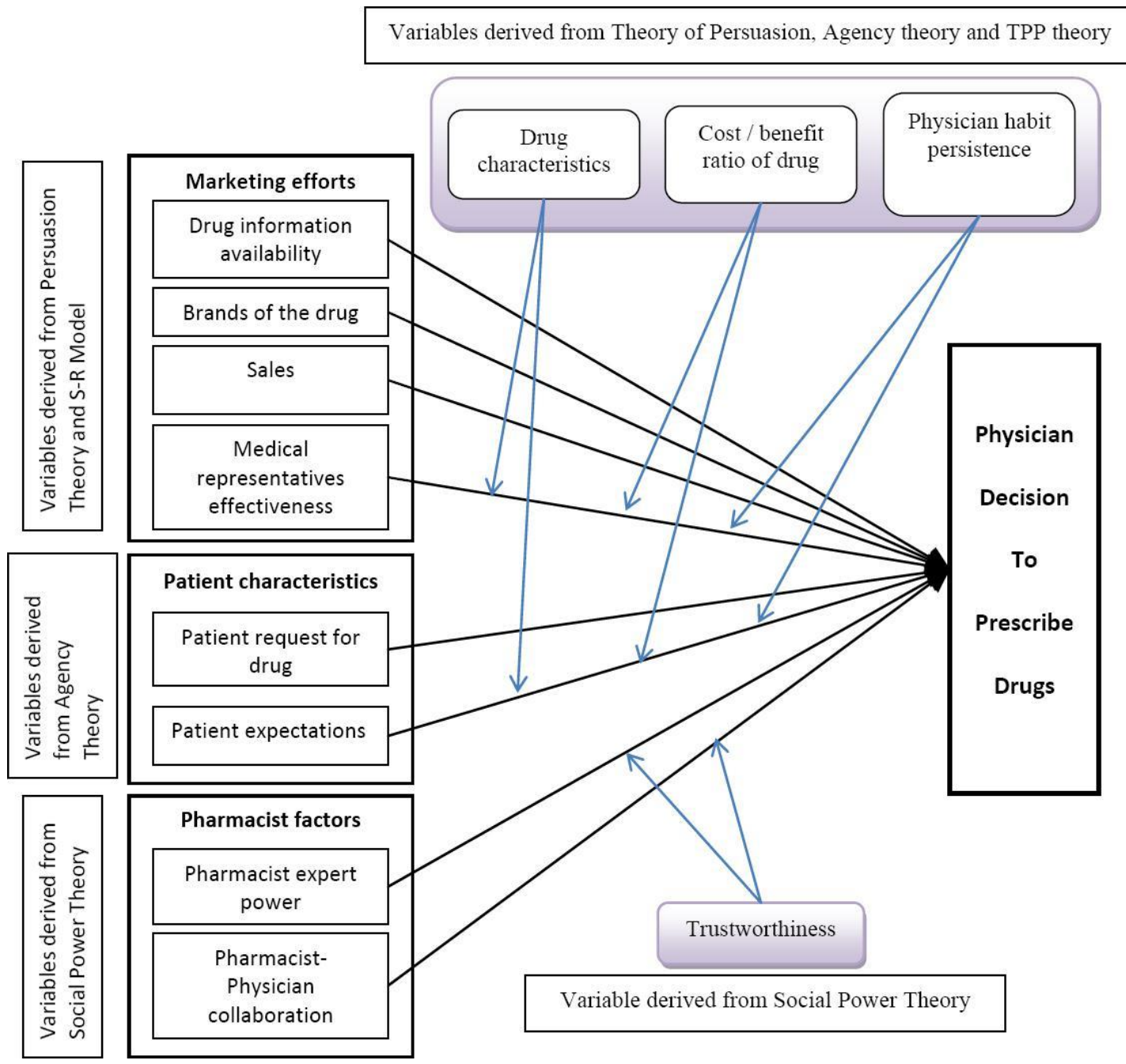

Figure 2.1: Theoretical Framework

Source: Prescribing decisions Models (Ali Murshid \& Mohaidin, 2017).

\section{Conceptual Framework}

According to Creswell (2014) the conceptual framework is a diagram or a tool that is used to make the reader understand more about a phenomenon. The conceptual framework is a tool that helps one to describe in diagram form the association that is there between the study variables. The main model in the study hypothesizes that, rational use of psychotropic medicine is influenced by prescribing indicators, patient care factors, health facility factors and complementary factors. This relationship is portrayed in figure 2.2 . 


\section{Independent Variable}

Figure 2.2: Conceptual Frame work

\section{Dependent Variable}

\section{Research Design}

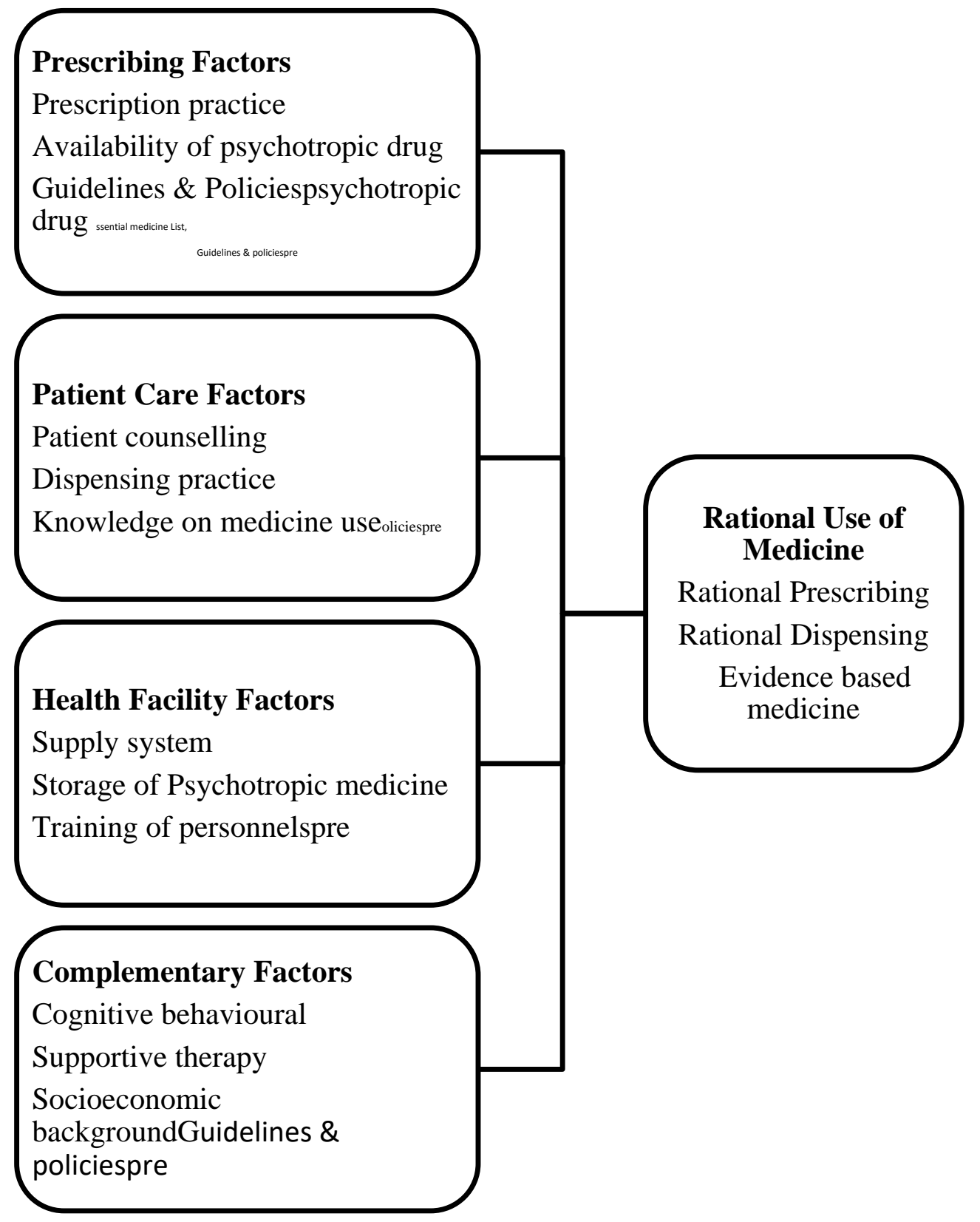

\section{RESEARCH METHODOLOGY}

\section{Introduction}

This section summarises all the methods that were utilized to achieve the objectives of this study. This chapter had inclusive of the research design, the research population, the right sample procedure to guide the researcher, it explains how data was collected and what instrument was used, and finally the methods of data analysis and presentation.
This study exercised the use of quantitative, descriptive \& correlational methods; structured Likert scale questionnaire was used to collect the data from the field. Correlation design was used to correlate independent variables and dependent variables, while the quantitative was used to get the inferential information for this study.

\section{Target Population}

Population is the total number of persons or items that were used to help carry out a study that is comprehensive and well detailed (Meyers, Gamst \& Guarino, 2016). In this study, the study 
population for this study were prescriber and dispensers working at Mathari National teaching and referral hospital at the time of study. The target population for this study was 125 , both prescribers and dispensers.

\section{Sample Size and Sampling Procedure Sample Size determination}

A sample can be defined as the subset of a population (Hair, 2011). Sampling is defined as it is the process of selecting a small number of individuals from the population size. This selection is intended to be a representation of the larger group; it has characteristics of the entire population size.

According to Fischer (2012) formula, at acceptable error of 5\% and occurrence of $50 \%$ the sample size was:

$$
n=\frac{Z^{2} p q}{d^{2}}
$$

Where

$\mathbf{n}=$ sample size

$\boldsymbol{Z}^{2}=$ Standard error from mean corresponds to $95 \%$ confidence interval $=1.96$,

$\boldsymbol{p}=$ proportion of the population with the desired characteristics $q=1-p=1-0.5=0.5$

$d(0.05)=$ Permissible error in the estimate of $\mathrm{P}$

Thus, with permissible error of $5 \%$, the sample size is:

$$
\begin{aligned}
n & =\frac{(1.96)^{2} \times .5 \times .5}{(0.05)^{2}} \\
n & =384.16^{(28)}
\end{aligned}
$$

$\mathrm{n} \approx 384$ Thus, the sample size is 384 .

The total of healthcare professionals at the Mathari National Teaching \& Referral Hospital, Nairobi is 125 as tabulated in Table 3.1

Table 3.1: Distribution of Prescribers and Dispensers at the facility

\begin{tabular}{ll}
\hline DESIGNATION & NUMBERS \\
\hline Doctors & 85 \\
Clinical officers & 5 \\
Pharmacist & 20 \\
Pharmaceutical Technologist & 5 \\
Nurses (Community Psychiatric) & 10 \\
TOTAL & $\mathbf{1 2 5}$ \\
\hline
\end{tabular}

Sample size calculation was based on Daniel's formula (1999) for estimating a population proportion for a finite population;

Where:

$$
n \geq \frac{N Z_{\alpha / 2}^{2} P(1-P)}{d^{2}(N-1)+Z_{\alpha / 2}^{2} P(1-P)}
$$

$\mathrm{n}=$ minimum sample size required

$\mathrm{N}=$ Total estimated population of prescribers and dispensers are $(\mathrm{N}=125)$

$Z_{\alpha / 2}=$ Standard normal distribution critical value at $\alpha$-level of significance $\left(\alpha=0.05, Z_{\alpha / 2}=1.96\right)$

$\mathrm{P}=$ Estimated proportion of prescribers and dispensers with say good knowledge of rational use of the psychotropic medicines ( $P$ was set at 0.5 because there's no available information from literature) $\mathrm{d}=$ Desired margin of error $(\mathrm{d}=0.05)$

Thus,

$$
\mathrm{n}=\frac{125}{(0.05)^{2}(125-1)+(1.96)^{2}(0.5 \times 0.5)}
$$

$\mathrm{n}=95$ sample size used for this study

The study used stratified sampling whereby the population are put on different strata based on the cadre. The sample size is then divided proportionately by percentage of the total population.

\begin{tabular}{|c|c|c|c|}
\hline \multicolumn{2}{|c|}{ Population } & Sampling Frame & Sample Size \\
\hline Doctors & 85 & 68 & 65 \\
\hline Clinical officers & 5 & 4 & 4 \\
\hline Pharmacists & 20 & 16 & 15 \\
\hline Pharmaceutical Technologist & 5 & 4 & 4 \\
\hline Community Psychiatry Nurses & 10 & 8 & 8 \\
\hline Total & 125 & $100 \%$ & 96 \\
\hline
\end{tabular}
That is, the total population per cadre over the general population multiplied by the determinant sample size. Out of the sample size in each stratum, simple random sampling is used to get the respondents. Sample size distribution is presented in Table 3.2

Table 3.2: Sample size Distribution

\section{Instrumentation}


By using following four key indicators of rational drug use data was collected: prescribing factors, patient care factors, health facility factors, and complementary factors using Likert scale questionnaire containing closed ended questions.

\section{Pre-Test}

To refine the information assortment instrument, a pre-test was done at Port Reitz Sub County Hospital, utilizing an example size of 30 respondents that won't be engaged with the primary examination.

\section{Validity of Instruments}

This means the determination of accuracy for information that was measured and determines how correct or incorrect the information is. The data collection tool borrowed aspects of the recommended WHO indicators for the rational use of medicines and tailored it to the study site Mathari National Teaching \& Referral Hospital (MNTRH) setting. Accuracy of the questionnaire was enhanced through advise from the supervisors and an expert in psychiatry.

\section{Reliability of Instruments}

This is where there can be more than one outcome from a research with a single methodology and the result can still be dependent on. It is concerned with establishing consistency within repeated time (Mugenda \& Mugenda, 2009). The total reliability index was 0.902 for 58 items of the questionnaire. A coefficient of between 0.6-1.0 was deemed acceptable for consistency. The closer Cronbach's alpha is to 1, the higher the internal consistency reliability, (Sekaran, 2002).

\section{Methods of Data Collection}

This study used drop and pick later method as one way of data collection. In addition, due to corona virus pandemic there were restrictions in the institute, therefore the researcher also sent the questionnaire via email to those who were not available at work place. The respondents were given two weeks to respond to the questionnaire. The questionnaire has close ended with Likert scale instruments of all variables.

\section{Operational Definition of Variables}

\begin{tabular}{|c|c|c|c|}
\hline Independent Variables & Indicators & $\begin{array}{l}\text { Measurement } \\
\text { Scale }\end{array}$ & $\begin{array}{l}\text { Type of statistical } \\
\text { analysis }\end{array}$ \\
\hline Prescribing Factor & $\begin{array}{l}\text { Perception of } \\
\text { prescribing } \\
\text { Availability of drugs } \\
\text { Policies and Guidelines }\end{array}$ & Likert Scale & $\begin{array}{l}\text { Descriptive } \\
\text { Inferential }\end{array}$ \\
\hline Patient care factor & $\begin{array}{l}\text { Patient counselling } \\
\text { Dispensing practice } \\
\text { Knowledge } \\
\text { medicines use }\end{array}$ & Likert Scale & Descriptive \\
\hline Health facility factors & $\begin{array}{l}\text { Supply system } \\
\text { Psychiatric medicine } \\
\text { storage }\end{array}$ & Likert Scale & Descriptive \\
\hline $\begin{array}{l}\text { Complementary factor } \\
\text { that affect the drug use }\end{array}$ & $\begin{array}{l}\text { Training of personal } \\
\text { Cognitive behavioural } \\
\text { Supportive therapy } \\
\text { Socio economic } \\
\text { background }\end{array}$ & Likert scale & Descriptive \\
\hline $\begin{array}{l}\text { Dependent Variable } \\
\text { Rational use of } \\
\text { Psychiatric medicines }\end{array}$ & $\begin{array}{l}\text { Rational Prescribing } \\
\text { Rational Dispensing } \\
\text { Evidence based } \\
\text { Medicine }\end{array}$ & Likert Scale & Descriptive \\
\hline
\end{tabular}

\section{Method of Data Analysis}

Quantitative data analysis was done with the use of SPSS Version 23. The Mean Score and standard deviations were used to analyse the descriptive variables in this study. The test statistics used were P-values, Spearman Rho (r), mean scores, standard deviations. The research questions in this study were tested using
Spearman Rho (r) and its corresponding P-Value. Where P-values were less than 0.05 , the study concluded that statistical evidence is available for each variable whose p-value was 0.05 and below while insignificant relationships were for those with P-values above 0.05. Likert based questions were analysed using mean scores for each question asked. A mean score above 3.4 indicates 
agreement while those below 3.4 indicated disagreements, where 1 was strongly disagree and 5 was strongly agree.

Correlational analysis was done to establish the significance of each variable on the dependent variable. This was shown by the value of (r) and its corresponding P-value. The Rho lies between 0.0 and 1.0. The more closely the value of $r$ is to 1.0 , the stronger the relationship and vice versa. The following functional relationship was used to obtain the model used in this study:

\section{Empirical Model}

The factors influencing rational use of psychotropic medicines were assessed using the following multiple linear relationship.

$Y=\beta_{0}+\beta_{1} X_{1}+\beta_{2} X_{2}+\beta_{3} X_{3}+\beta_{4} X_{4}+\varepsilon$

Where:

$\mathrm{Y}=$ Rational use of psychotropic medicines

$\beta_{0}=$ intercept

$\beta_{1} X_{1}=$ linear effect of Prescribing Factors

$\beta_{2} X_{2}=$ linear effect of Patient Care Factors

$\beta_{3} X_{3}=$ linear effect of Health Facility factors

$\beta_{4} X_{4}=$ linear effect of Complementary Factors

$\varepsilon=$ predictive error

\section{RESULTS AND DISCUSSION}

\section{Introduction}

This part covers research results and discussion based on the data collected and analysed. This section covers the demographic characteristics of the respondents; the descriptive statistics of both the dependent variable and independent variables, bivariate analysis statistics and the multivariate analysis statistics.

\section{Response Rate}

From a sample of 96, 93 respondents returned completely filled questionnaires. The response rate was $97 \%$ which is considered acceptable in research. The total reliability index was 0.902 for 58 items of the questionnaire. A coefficient of between 0.6-1.0 was deemed acceptable for consistency. The closer Cronbach's alpha is to 1 , the higher the internal consistency reliability, (Sekaran, 2002). Refer to Table 4.1

\section{Table 4.1 Reliability of Instruments}

\begin{tabular}{lc}
\hline Variable & Number of items \\
\hline Prescribing factors (Xi) & 16 \\
Patient factors (Xii) & 11 \\
Health Facility factors (Xiii) & 11 \\
Complementary factors (Xiv) & 9 \\
Rational Use (Y) & 11 \\
\hline All items & $\mathbf{5 8}$ \\
\hline
\end{tabular}

\section{Demographic Characteristics of the Respondents}

The research sought to find out the demographic characteristics of the respondents in terms of their gender, age, job cadre, education level and years of service. More than half of the respondents 58 (62\%) were female. Majority 45(49\%) were 31-40 years, majority were doctors 60(65\%), held a Bachelor's Degree $47(51 \%)$, and have worked less than 5 years $53(57 \%)$. About $47(50 \%)$ have prescribed for more than 6 years, indicating a good understanding of prescribing and dispensing practices. $43(45 \%)$ of the respondents attend to more than 50 patients daily mean 24-50 hours daily, which signifies heavy workload. The demographic results of this study are presented in Table 4.2.

Table 4.2 Demographic Characteristics of Respondents

\begin{tabular}{lc}
\hline Characteristics of Respondents & $\begin{array}{c}\text { No. of Respondents } \\
(\%)\end{array}$ \\
\hline Gender & $35(38)$ \\
Male & $58(62)$ \\
Female & $\mathbf{9 3}(\mathbf{1 0 0})$ \\
Total & \\
\hline Age & $17(18)$ \\
Below 30 years & $45(49)$ \\
$31-40$ years & $17(18)$ \\
$41-50$ years & $11(12)$ \\
51-60 Years & $3(03)$ \\
60 and above & $\mathbf{9 3 ( 1 0 0 )}$ \\
Total & \\
\hline Professional Cadre & $60(65)$ \\
Doctor & $15(16)$ \\
Pharmacist & $4(04)$ \\
Clinical Officer & $4(04)$ \\
Pharmaceutical technologist & $10(11)$ \\
Nurses & $\mathbf{9 3 ( 1 0 0 )}$ \\
Total & \\
\hline Education Level & $12(13)$ \\
Diploma & $47(51)$ \\
Bachelor's Degree & \\
\hline
\end{tabular}




\begin{tabular}{lc}
\hline Master's Degree & $33(36)$ \\
PhD & $1(01)$ \\
Total & $\mathbf{9 3}(\mathbf{1 0 0})$ \\
\hline Years working at this facility & \\
Less than 5 years & $53(57)$ \\
5-10 years & $22(23)$ \\
10-15 years & $7(08)$ \\
More than 15 years & $11(12)$ \\
Total & $\mathbf{9 3}(\mathbf{1 0 0})$ \\
\hline Years Dispensing \& Prescribing & \\
Less than 1 year & $14(15)$ \\
Between 1-5 years & $32(35)$ \\
Between 6-10 years & $19(20)$ \\
More than 10 years & $28(30)$ \\
Total & $\mathbf{9 3}(\mathbf{1 0 0})$ \\
\hline Daily patients attended & \\
Less than 30 patients 1 & $21(23)$ \\
Between 30-50 patients & $29(31)$ \\
Between 50-100 patients & $23(24)$ \\
More than 100 patients & $20(22)$ \\
Total & $\mathbf{9 3}(\mathbf{1 0 0})$ \\
\hline
\end{tabular}

\section{Descriptive Statistics of Prescribing Factors}

The prescribing factors were focused on assessing the health workers understanding of the prescription practice, availability of medicine and use of drug availability List/ essential medicine list, guidelines and policies. Data on prescribing factors was collected using a five-point Likert scale questionnaire with Strongly agree as 5, agree as 4, Not sure as 3, disagree as 2 and strongly disagree as 1. A Mean cut off of above 3.4 set as agree and below 3.4 being disagree, the results show that majority of the respondents agreed to often prescribe medicine using generic name $(\mathrm{M}=3.45 ; \mathrm{SD}=$ $0.98)$ which are cheaper than branded medicine $(\mathrm{M}=3.81 ; \mathrm{SD}=$ 1.16). Respondents disagreed that branded medicine are more effective than generic medicines $(\mathrm{M}=2.56$; $\mathrm{SD}=1.09)$. Worth noting is that the respondents disagreed to having policies, standard treatment guidelines and essential medicines list, though they were provided with available medicines list. They agreed to the fact that standard treatment guidelines are helpful source of information and improving supply of psychotropic drugs would improve service delivery. It was noted that there in inadequate supply of psychotropic medicine in the hospital. Injectable psychotropic medicines were not preferred more than oral medicines, nor were they considered to be more effective than the oral medicines. See Table 4.3.

Table 4.3 Descriptive Statistics of Prescribing Factor

\begin{tabular}{rlrl}
\hline & Statement & Mean & $\begin{array}{l}\text { Std. } \\
\text { Deviation }\end{array}$ \\
\hline i. & I usually prescribe all medicine using brand name & 2.49 & 0.93 \\
ii. & Branded medicines are more effective than generic medicine & 2.56 & 1.09 \\
iii. $\quad$ I often prescribe medicine by using generic name & 3.45 & 0.98 \\
iv. $\quad$ Generic medicines are usually cheaper than branded medicine & 3.81 & 1.16 \\
v. $\quad$ I usually ensure that prescriptions must have minimum one injectable & 2.06 & 0.86 \\
vi. $\quad$ Injections are more often prescribed compare to oral medication & 2.10 & 0.82 \\
vii. $\quad$ Injectable are more effective than oral medication & 2.87 & 0.99 \\
viii. $\quad$ There is an adequate supply of psychotropic medicine in the hospital. & 2.56 & 1.12 \\
ix. $\quad$ Improving supply of psychotropic drugs will improve service delivery & 4.14 & 1.12 \\
x. $\quad$ I have a copy of the Standard treatment guidelines and Essential & 2.99 & 1.22 \\
xi. $\quad$ I have a copy of the drugs availability list & 3.56 & 1.13 \\
\hline
\end{tabular}




\begin{tabular}{clcc}
\hline xii. & I have access to the policies and standard treatment guidelines & 3.11 & 1.16 \\
xiii. $\quad$ I understand the facilities policies and standard treatment guidelines & 3.28 & 1.14 \\
xiv. $\quad$ This standard treatment guidelines are helpful source of information & 4.14 & 0.95 \\
xv. & We have an active Drug and Therapeutics committee & 2.98 & 0.99 \\
xvi. & The Drug and therapeutics committee has developed a hospital \\
& formulary which is reviewed periodically & 2.76 & 0.98 \\
\hline
\end{tabular}

This study established that providers did not have preference for injectable medicine; neither did they perceive them to be more effective. This study does not therefore not agree with Fujita, Moles and Chen, (2018) who established that most prescription solution had injectable arrangements and prescribers preferred injectable medication as compared to oral medicines. Furthermore, the authors in their study established that $85.26 \%$ of medications were from fundamental medications list, unlike in this study where the prescribers are not provided with the essential medicines list. However, this study agrees with Fujita, Moles and Chen, (2018) who, from their examination, identified that remedies had drugs recommended by nonexclusive name. This study found that often prescribers prefer prescribing medicines using generic names, which can probably be explained by the fact that they are often cheaper than branded medicine. Alam, et al., (2016) conducted a study on the prescribing factors influencing rational use of psychotropic in the outpatient section in a hospital in Bangladesh in their study, there was a $48.3 \%$ of combination of oral and parenteral drugs in prescriptions and majority of drugs were prescribed by brand names. The findings of Alam, et al., (2016) are in line with the findings of the current study because the respondents indicated to prescribing medicine using generic names and combination of both oral and injectable, without a preference for injectable. The findings of this study indicate that there is inadequate supply of psychotropic medicine in the hospital. These findings are similar to a study conducted in Ghana at the Psychiatric hospital which revealed that long-acting antipsychotic injections were unavailable and $27.6 \%$ reported unavailability of other psychiatric medicines (Ashong et al., 2018). In developing countries lack of regular availability of psychiatric medicine, poor accessibility of health care facility may have relevant impact on irregular use of medicines and adherence (Barbui, 2015). Furthermore, the respondents indicated that improving supply of psychotropic drugs will improve service delivery, which is in line with what MSH, (2012) stated that psychotropic drug use is affected by many factors like drug availability, provider experience, economic influences, cultural factors, community belief systems, and others.

This study reveals non existing policies, standard treatment guidelines and essential medicines list, though respondents were provided with available medicines list. Similar results were found by (Bigdeli et al., 2014) who states that in low and middle income countries $50 \%$ of medicine are used inappropriately, as per world medicine situation 2011, only $30-40 \%$ patients are treated according to clinical guidelines and only $50 \%$ patient adhere to treatment regimen. The respondents in the current study however agreed to the fact that standard treatment guidelines are helpful source of information and improving supply of psychotropic drugs would improve service delivery. The opinion of the respondents is in agreement with (WHO, 2002) which states that in order to improve rational drug use, countries have to identify and promote successful policies, develop and update their treatment guidelines, national essential medicine lists and formularies, supporting training program on rational use of medicines and developing effective system for medicine information. Individual countries have developed their own essential medicine list (EDL), for Kenya essential medicine list (KEML 2019) is the current essential drug list. Many healthcare facilities have compiled their own drug formulary borrows a leaf from the country's essential medical list.

\section{Descriptive Statistics of Patient Care Factors}

The objective on patient factors was to assess the prescribers and dispensers understanding of the patient consultation process, dispensing practice and patients' knowledge on medicine use. Data on patient factors was collected using a five-point Likert scale questionnaire with Strongly agree as 5, agree as 4 , Not sure as 3, disagree as 2 and strongly disagree as 1 . A Mean cut off of above 3.4 set as agree and below 3.4 being disagree. Majority of the respondents agree with the statement that they consult with patients before giving a prescription, they observe privacy when dispensing medicine, and that the medicines dispensed are well labelled. However, the respondents disagree to the fact that they have enough time to explain medication to patients and to the fact that they lack adequate time to package and label the medicine appropriately. This may be explained by the fact that $72(70 \%)$ of the respondents indicated to attend to more than 30 psychiatric patients per day with $23(22 \%)$ actually attending to more than 100 patients in a day. This may inhibit spending adequate time with the patient and completing all the processes adequately due to heavy work load. Though the medicine prescribed are often generic and affordable, the respondents agree to the fact that sometimes prescribed medicine is not dispensed due to it being unaffordable to patients who often lack health insurance or even money to pay for the medicine. The respondents are in agreement to the fact that they inform patients on frequency of medication and repeat to them how to take medicine and inform patients on side effects of the medicine. See Table 4.4

The findings of this study on respondents agreeing to giving patients adequate information on frequency of medication and side effects is in agreement with Abebaw, et al., (2016) who uncovered in their study that the greater part of the customers knew about right measurements of the medications they were given. The results of this study are also in agreement with Basrowi, et al., (2018) who established that patients' knowledge, self-assurance 
and attitude were the patient care factors that were strongly associated with rational use of medicine. In this study patient knowledge may be implied from the information exchange to patients by the prescribers and the dispensers.

Table 4.4 Descriptive Statistics of Patient Care Factors

\begin{tabular}{|c|c|c|c|}
\hline & Statement & Mean & $\begin{array}{l}\text { Std. } \\
\text { Deviation }\end{array}$ \\
\hline i. & I usually consult with the patient before giving a prescription & 3.72 & 1.00 \\
\hline ii. & I usually observe privacy when dispensing medicine to patients & 3.52 & 1.07 \\
\hline iii. & I have sufficient time to explain medication to patient & 3.41 & 1.03 \\
\hline iv. & All medicine dispensed at the pharmacy are labelled & 3.76 & 0.85 \\
\hline $\mathrm{v}$. & $\begin{array}{l}\text { I usually write Medicine strength on each dispensed medicine } \\
\text { envelope }\end{array}$ & 3.59 & 1.01 \\
\hline vi. & $\begin{array}{l}\text { I have enough time to package and label the medicine appropriately } \\
\text { despite the workload }\end{array}$ & 3.27 & 0.95 \\
\hline vii. & $\begin{array}{l}\text { We have some drugs that are frequently prescribed and not dispensed } \\
\text { due to lack of health insurance cover }\end{array}$ & 3.52 & 1.06 \\
\hline viii. & $\begin{array}{l}\text { We have some drugs that are frequently prescribed and not dispensed } \\
\text { due to affordability of psychotropics drugs }\end{array}$ & 3.66 & 1.06 \\
\hline ix. & I often give knowledge to the patient on frequency of medication & 4.05 & 0.89 \\
\hline $\mathrm{x}$. & I often ask patient to repeat how do they take medicine & 3.57 & 1.02 \\
\hline xi. & I often inform patient on side effects of medicine. & 3.71 & 0.89 \\
\hline
\end{tabular}

Further Endalkachew, Begashaw and Hailu (2017) established that dominant part of the patients in their study had satisfactory information on the best way to take the medicine endorsed and knew the insurance, quality and name of the medications. Therefore, information exchange is paramount in rational drug use by both the patient and the prescribers and dispensers. Respondents in the current study agreed to have sufficient time to explain medication to patients. WHO, (1993) outlines that to improve rational drug use the patient must receive sufficient consultation time. Main aim of rational use of drug is to provide better pharmaceutical care, (WHO, 2002), in this study the respondents agreed to often give knowledge to the patient on frequency of medication, often ask patient to repeat how do they take medicine and often inform patient on side effects of medicine, which are viewed as good pharmaceutical care. In addition, the respondents agreed that all medicine dispensed at the pharmacy are labelled and that the medicine strength is usually written on each dispensed medicine envelope. If correct amount and strength of psychotropic drugs, after appropriate packaging and labelling if not given to right person with appropriate instruction may cause serious consequences, (Sisay et al., 2017). WHO, (2002) further states that the main aim of the patient care factors is to dispense well labelled appropriate medicine, and to prepare patient how to deal with the medicines which have been dispensed measured by counselling time and knowledge on medicine use. Results of a study done in Ethiopia shows that the average consultation and dispensing times were 5.6 and $2.7 \mathrm{~min}$, respectively use by dispensers, among the drugs dispensed, 64\% were properly labelled and the proportion of patients with satisfactory information about medicines was 69 \% (Carl et al, 2013).

Respondents indicated to have had sufficient time to explain medication to patient and to package and label the medicine appropriately despite the workload. These statements scored very low and would adversely affect rational use of medicine. Patient consultation is essential for the rational use of drugs. Consultation time is very important for prescribers and dispensers for the potential quality of diagnosis and treatments (MSH, 2012c). Shortage of staff, excessive workload and poor set up of the dispensary could result in minimal time for consultation and giving out the medicine which may lead to scanty information about their treatment and medication (Bilal et al., 2016).

\section{Descriptive Statistics of Health Facility Factors}

Facility factors sought to understand the respondents understanding of the supply system of the psychotropic medicine, whether staff are trained on rational use of these medicines and the storage mechanisms in place. Data on facility factors was collected using a five-point Likert scale questionnaire with Strongly agree as 5, agree as 4 , Not sure as 3 , disagree as 2 and strongly disagree 
as 1. A Mean cut off of above 3.4 was set as agree and below 3.4 being disagree. The findings are presented in Table 4.5

Most of the responses on the supply system scored below the 3.4 cut off point. The respondents seem to disagree to the fact that psychotropic products are selected and procured from the Essential Drug List. This is not in agreement with what they mentioned under prescribing factors that they are not provided with essential medicines list nor are they provided with the standard treatment guidelines. Indeed, the respondents also disagreed to using consumption data to forecast drugs they require, neither do they calculate well defined procurement period to avoid stock outs. Respondents also disagreed to there being in existence a system to inform the prescriber about pharmacy stock out, neither there being enough room/space for storage of drugs. There are no frequent trainings on the rational use of psychotropic medicines, neither are new staff taken through an induction training on the rational drug use as part of orientation process, nor is essential medicines concept a part of the basic curriculum in most health training institutions /universities. Respondents agreed to there being bin cards and monthly stock counts.

Table 4.5 Descriptive Statistics of Health Facility Factors

\begin{tabular}{|c|c|c|c|}
\hline & Statement & Mean & $\begin{array}{l}\text { Std. } \\
\text { Deviation }\end{array}$ \\
\hline i. & $\begin{array}{l}\text { All Psychotropic products are selected and procured from the Essential } \\
\text { Drug List }\end{array}$ & 3.20 & 0.85 \\
\hline ii. & I use the consumption data to forecast drugs to procure & 3.34 & 0.88 \\
\hline iii. & I do calculate well defined procurement period to avoid stock outs & 3.22 & 0.83 \\
\hline iv. & There is a system to inform the prescriber about pharmacy stock out & 3.11 & 1.06 \\
\hline v. & $\begin{array}{l}\text { The drug store is secure and locked to prevent theft and unauthorized } \\
\text { access }\end{array}$ & 3.41 & 0.92 \\
\hline vi. & I have enough room/space for storage of drugs & 3.31 & 0.98 \\
\hline vii. & I often carry out stock count on monthly basis & 3.40 & 0.86 \\
\hline viii. & $\begin{array}{l}\text { I have up to date and correctly filled stock/bin cards for the control of } \\
\text { stocks }\end{array}$ & 3.44 & 0.85 \\
\hline ix. & $\begin{array}{l}\text { There is frequent training on the rational use of psychotropic } \\
\text { medicines. }\end{array}$ & 2.75 & 1.03 \\
\hline x. & $\begin{array}{l}\text { New staff are taken through an induction training on the rational drug } \\
\text { use as part of orientation process }\end{array}$ & 2.91 & 1.05 \\
\hline xi. & $\begin{array}{l}\text { The essential medicines concept is generally a part of the basic } \\
\text { curriculum in most health training institutions /universities }\end{array}$ & 3.33 & 1.00 \\
\hline
\end{tabular}

Richard \& Akosua, (2016) established that the major contributors for the irrational use of drug are from patients, prescribers, the workplace, the supply system, regulation, drug information and misinformation, and combinations of these. Further the authors established that there are many internal and external factors affect irrational use of medicine, like the healthcare worker may lack adequate training, inadequate continuing education may result in outdates prescribing practice. In low- and Middle-income countries healthcare worker lacks training. This study demonstrates a similar trend of inadequate training among health care providers due to resources constraints.

\section{Descriptive Statistics of Complementary Factors}

The researcher sought the respondents understanding of the complementary factors. The factors assessed were cognitive behavioural therapy, supportive therapy and socioeconomic background of the patients and how they influence rational use of psychotropic medicine. Data on complementary factors was collected using a five-point Likert scale questionnaire with 
Strongly agree as 5, agree as 4 , Not sure as 3, disagree as 2 and strongly disagree as 1 . A Mean cut off of above 3.4 was set as agree and below 3.4 being disagree. The findings are presented in Table 4.6

The respondents agreed to the fact that patient cultural belief, community stigma, psychosocial support, patient socio economic status and having a health insurance influence use of psychotropic medicines. This is as a result of respondents scoring above 3.4 in each of these statements. There is a general agreement that there is equity in delivery of health service among patients as most respondents disagreed $(\mathrm{M}=3.10 ; \mathrm{SD}=1.30)$ to patients with low social economic factor are always given cheaper medicine. The findings of this study is in agreement with MSH, (2012), who established that psychotropic drug use is affected by many factors like drug availability, provider experience, economic influences, cultural factors, community belief systems, and others. Drug use patterns reflect human behaviour and must be viewed from a social science perspective other than a biomedical perspective.

Table 4.6 Descriptive Statistics of Complementary Factors

\begin{tabular}{|c|c|c|c|}
\hline & Statement & Mean & Std. Deviation \\
\hline i. & Patients' Cultural belief influence the treatment & 4.05 & 0.86 \\
\hline ii. & Community stigma influence the use of psychotropic medicine & 4.12 & 0.99 \\
\hline iii. & Patient demand influence the rational use of psychotropic medicine & 3.52 & 1.01 \\
\hline iv. & Use of appropriate diagnostic equipment improve service delivery & 4.26 & 0.97 \\
\hline $\mathrm{v}$. & Psycho-social support influences the use of psychotropic medicine & 4.28 & 1.04 \\
\hline vi. & Use of alternative therapy influences the use of psychotropic medicine. & 3.86 & 0.98 \\
\hline vii. & $\begin{array}{l}\text { Patient's socio-economic status influences the rational use of } \\
\text { psychotropic medicine }\end{array}$ & 3.99 & 1.14 \\
\hline viii. & $\begin{array}{l}\text { Patients of low socio-economic status should always be prescribed } \\
\text { cheaper drugs. }\end{array}$ & 3.10 & 1.30 \\
\hline ix. & $\begin{array}{l}\text { Health insurance cover influences the rational use of psychotropic } \\
\text { medicine }\end{array}$ & 3.89 & 1.13 \\
\hline
\end{tabular}

Further the World Council of Churches, (2006) stated that people often have many reasons for using medicines irrationally, which include poor knowledge, skills or independent information, unrestricted availability of medicines, lack of drug availability, overwork of health personnel, inappropriate promotion.

\section{Descriptive Statistics of Rational Use of Psychotropic Medicine}

The researcher sought the respondents understanding of rational use of psychotropic medicine. Data on rational use of psychotropic medicine was collected using a five-point Likert scale questionnaire with Strongly agree as 5, agree as 4 , Not sure as 3 , disagree as 2 and strongly disagree as 1 . A Mean cut off of above 3.4 was set as agree and below 3.4 being disagree. The findings are presented in Table 4.7

Table 4.7 Descriptive Statistics of Rational Use of Psychotropic Medicine

\begin{tabular}{clcc}
\hline & Statement & Mean & $\begin{array}{l}\text { Std. } \\
\text { Deviation }\end{array}$ \\
\hline 1. & All prescribed drugs are from the Essential Drug List & 2.74 & 1.09 \\
2. & All prescriptions are appropriate for the diagnosis & 3.30 & 1.13 \\
\hline
\end{tabular}


3. Prescriptions are clear and legible

4. Dispensed drugs are well labelled with clear instructions

5. Dispensed drugs are well packed

6. Each patient is given drug information

7. Each patient is counselled during dispensing

8. All medication errors are captured and corrected

9. Relevant investigations are carried out prior to making a diagnosis

10. Patient complaints and adverse drug reactions are reported and appropriate remedy actions taken

11. We are updated on new trends in treatment through workshops and Continuous Medical Education

$3.32 \quad 1.03$

$3.57 \quad 0.97$

3.620 .88

$3.33 \quad 0.96$

$3.37 \quad 0.93$

$3.16 \quad 1.00$

$3.28 \quad 1.17$

3.45

3.44

1.11
Majority of the respondents disagreed to prescribing medicines from the essential medicines list, disagreed on the statement that prescriptions are appropriate for the diagnosis, also disagreed to prescriptions being clear and legible, disagreed to each patient being given drug information, disagreed to each patient being counselled during dispensing, disagreed to all medication errors being captured and corrected and also disagreed to relevant investigations are carried out prior to making a diagnosis. The results of this variable may be explained by earlier responses which indicate that more than $70 \%$ of the respondents mentioned that they attend to more than 30 patients in a day, and this could lead to workload and fatigue, which may lead to the staff not spending adequate time with each patient, which could result to failure in counselling patients during dispensing and failure in providing them with adequate information and inadequate investigations before making a diagnosis.

According to WHO, (2017) for the appropriate use of drugs the patient must get medication appropriate to their medical requirements, the findings of this study are contrary to this requirement as majority disagreed to the statement that all prescriptions are appropriate for the diagnosis and that relevant investigations are carried out prior to making a diagnosis, the respondents also disagreed to all medication errors being captured and corrected. There are many strategies that have been put for prescribing practice. These strategies can be classified into three classes, namely, educational, managerial and regulatory (Charles, 2014) one of the managerial strategies is having a maximum number of drugs per prescription and structured prescription forms, this study however reveals that most prescriptions are not clear and legible. In addition, the results of this study indicate that most prescriptions are not made from the Essential drug lists (EDL) which according to WHO, (1997) helps in promoting rational prescribing. This study reveals that only a percentage of the drugs is prescribed from the EDL, which is similar to a study done in Nepal which revealed that $29.48 \%$ medicines are prescribed form EDL (Padmanathan \& Roy, 2001).

The results of this study reveal that drugs are well packed and labelled before being dispensed, these are some of the good dispensing practices as defined by Nandeshkumar et al., (2020). Adequately labelled drug packages/envelop contain at least patient's details, name of the medicine and information about when the drug should be taken. When the substandard labelling practice followed, it always has the potential to cause medication errors. Nandeshkumar et al., (2020) state that rational use of medicine involves dispensing medicine with clear instructions and in a package/envelope that maintains the efficacy of the medicine. The results of this study further reveal that patients are not always given drug information and counselling during dispensing which could be attributed to heavy workload. Wahome et al., (2019) established that pharmacists should offer guidance on the side effects, adverse drug reactions, advice on dietary precautions and information that is deemed necessary for the safety of the patient. This study reflect the shortcomings stated by MSH, (2012) that dispensing practice may be affected by lack of adequate knowledge, lack of material, due to heavy workload. Further, Basrowi, et al., (2018) established that knowledge, self-assurance and attitude were the patient care factors that were strongly associated with rational use of medicine among paediatricians in Indonesia.

\section{Relationship between independent and dependent variables Chi square Measure of Association}

Cross tabulation was done to establish whether there was a relationship between each independent variable and the dependent variable. The chi square was used to assess whether an association exists between the dependent and the independent variables. The results are presented in Table 4.8 . 
Table 4.8 Chi square Measure of Association

\begin{tabular}{lllll}
\hline Variable & $\begin{array}{l}\text { Sample } \\
\text { Size (n) }\end{array}$ & $\boldsymbol{\chi}^{\mathbf{2}}$ & Df & $\boldsymbol{p}$-value \\
\hline Prescribing factors & 93 & 733.449 & 644 & 0.008 \\
Patientcare Factors & 93 & 738.002 & 672 & 0.039 \\
Health Facility factors & 93 & 867.995 & 756 & 0.003 \\
Complementary Factors & 93 & 741.108 & 672 & 0.033 \\
\hline
\end{tabular}

The prescribing, patient care, health facility and complementary factors were significantly associated with rational use of psychotropic medicine in Mathari National Referral Hospital. The results were significant at $p<0.05$. The $p$-value indicates that these variables were not independent of each other and that there was a statistically significant relationship between the categorical variables.

\section{Spearman's rho bivariate analysis}

A Spearman's rho bivariate analysis was undertaken so as to determine the relationship between each independent variable and the dependent variable. Results shows that there was a positive relationship between the independent variables (prescribing factors, patient factors, health facility factors and complementary factors) and the dependent variable (Rational use of psychotropic medicines). The coefficient of correlation of prescribing practices $(r=0.397, p<0.001)$, patient factors $(r=0.289, p<0.05)$, health facility factors $(r=0.446, p<0.001)$ and complementary factors $(r=0.313, p<0.05)$ showed a positive relationship with rational use of psychotropic medicines. Worth noting is that though the relationship was significant it was below $r=0.5$, thus implying a weak relationship which one in particular was low or is it all of them. This can be attributed to the fact that the respondents did not see their role in rational drug use. See Table 4.9

Table 4.9 Bivariate Analysis-Correlation Coefficient

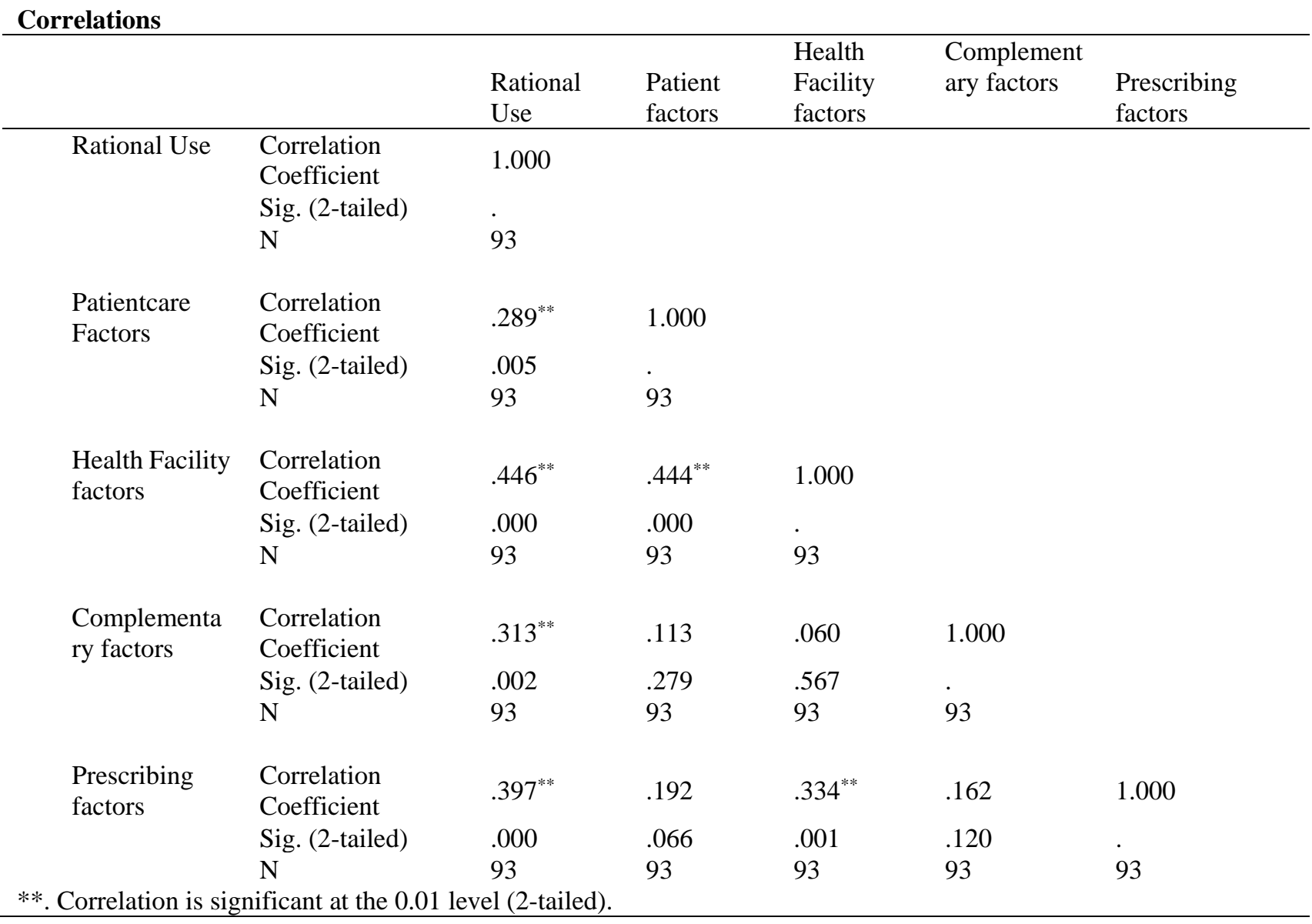

This study found a significant and positive relationship between prescribing factors and rational use of psychotropic medicine. This finding is in agreement with Maxwell, (2016) who identified rational prescribing as a key determinant in rational use of medicine. Charles, (2014) further identified three strategies influencing rational prescribing namely, educational, managerial 
and regulatory. These strategies have an influence on rational drug use. Examples of education strategies are Bulletins, seminars, printed materials and face-to-face intervention. Managerial strategies are generally restrictions on prescribing and they include cost restrictions, endorsement by higher qualified consultants, a maximum number of drugs per prescription and structured prescription forms. This study established that prescribers lack structured prescriptions, and the dispensers confirmed this by saying that the prescriptions are at times not clear.

This study also established that health facility factors had a significant and positive influence on rational prescribing. The health facility factors focused on supply chain factors such as: Essential Drug List, consumption data, defined procurement period, secured drug store, stock count, filled bin cards and training on the rational medicines use. The results of this study are in agreement with WHO, (1997) which recognised the supply chain factors contributed a lot in promoting rational use of medicine.

The findings of this study demonstrate a significant and positive relationship between patient care factors and rational use of medicine. The patient care factors took into consideration: Consulting with patients before giving a prescription, observing privacy when dispensing medicine to patients, having sufficient time to explain medication to patient, labelling all medicine dispensed at the pharmacy, writing medicine strength on each dispensed medicine envelope, having enough time to package and label the medicine appropriately, giving knowledge to the patient on frequency of medication, asking patients to repeat how do they take medicine and informing patient on side effects of medicine. These findings are in agreement with Nandeshkumar et al., (2020) who identifies patient factors as having an influence on rational medicines use. The authors emphasis that dispensing right drug to the correct patient, in the right dose and measure, with clear advices and in a package is a vital factor in ensuring rational use of medicine and maintaining the potency of the medicine. Having medicine envelope containing at least patient's details, details of medicine and detail instructions on when the drug should be taken, reduces medication errors, however dispensing practice may be affected by lack of adequate knowledge and lack of material due to heavy workload.

Finally, this study found a significant and positive association between complementary factors and rational use of medicine. The factors taken into consideration under complementary factors were: patient's cultural belief, community stigma, patient demand, psycho-social support and patient's socioeconomic status. These findings are in agreement with (MSH, 2012), Titus et al., (2000) and Basrowi, et al., (2018) who all established that complementary factors have an influence on rational medicines use. The findings of this study are also in agreement with Kirigia \& Sambo, (2003) who established that stigmatization, discrimination, knowledge, self-assurance and attitude were the patient care factors that were strongly associated with rational use of medicine. Further this study established that alternative therapy influences use of psychotropic medicines, these findings are similar to Sarris, et al., (2017) where the authors established that support for natural medication-alternative therapy, was an underlying factor in adherence to mental health treatment.

\section{Model summary}

The regression model in Table 4.10 specifies coefficient of determination $\mathrm{R}^{2}$ as 0.308 . This means that variables in this study explained about $30.8 \%$ of variations in rational use of psychotropic medicine. Adjusted $\mathrm{R}^{2}$ is used since the constant is not significant. This study further sought to establish the extent to which the independent variables (prescribing factors, patient factors, health facility factors and complementary factors) influence the dependent variable (Rational use of psychotropic medicines) Mathari National Teaching and Referral Hospital in Nairobi, Kenya. A Durbin-Watsons statisctics $>2$ indicates that there was no autocorrelation between the study variables. The summary model results in Table 4.11 shows that the overall Pvalue is less that $0.05(5 \%)$. This shows that the overall regression model is significant at the calculated $95 \%$ level of significant. It further inferred that the studied independent variables have significant influence on rational use of psychotropic medicines.

Table 4.10 Model Summary

\begin{tabular}{lllllll} 
Model & $\mathrm{R}$ & R Square & $\begin{array}{l}\text { Adjusted } \\
\text { Square }\end{array}$ & $\begin{array}{l}\text { R } \\
\text { Estimate }\end{array}$ & Durbin-Watson \\
\hline 1 & $.582^{\mathrm{a}}$ & .338 & .308 & 6.06406 & 2.168
\end{tabular}

a. Predictors: (Constant), prescribing factors, patient factors, health facility factors and complementary factors

b. Dependent Variable: Rational use of psychotropic medicines

Table 4.11 Analysis of Variance

\begin{tabular}{llllllll}
\hline Model & & Sum & of & & & \\
& & Squares & & df & Mean Square & F & Sig. \\
\hline 1 & Regression & 1654.464 & 4 & 413.616 & 11.248 & $.000^{\mathrm{b}}$ \\
& Residual & 3236.009 & 88 & 36.773 & & \\
& Total & 4890.473 & 92 & & & \\
\cline { 2 - 6 }
\end{tabular}


a. Dependent Variable: Rational use of psychotropic medicines

b. Predictors: (Constant), prescribing factors, patient factors, health facility factors and complementary factors

Table 4.12 Regression Weights

Collinearity statistics

\begin{tabular}{ll}
$\begin{array}{l}\text { Unstandardized } \\
\text { Coefficients }\end{array}$ & $\begin{array}{l}\text { Standardized } \\
\text { Coefficients }\end{array}$ \\
\hline
\end{tabular}

\begin{tabular}{llllllll} 
& \multicolumn{3}{c}{ Std. } & \multicolumn{3}{c}{ Toleranc } \\
Model & $\mathrm{B}$ & Error & Beta & $\mathrm{t}$ & $\mathrm{Sig}$. & $\mathrm{e}$ & VIF \\
\hline (Constant) & -.311 & 6.038 & & -.051 & .959 & & \\
Prescribing factors & .302 & .106 & .265 & 2.837 & .006 & .860 & 1.162 \\
Patient factors & .074 & .112 & .065 & .656 & .513 & .757 & 1.322 \\
Facility factors & .270 & .104 & .269 & 2.601 & .011 & .704 & 1.420 \\
Complementary factors & .275 & .103 & .242 & 2.674 & .009 & .921 & 1.086 \\
\hline
\end{tabular}

a. Dependent Variable: $\mathrm{Y}$

The VIF index shown in Table 4.12 is below 10 for all the variables indicating that there was no multicollinearity. The constant was not significant with $p>0.05$. This infers that the study variables under this study are important in determining rational use of psychotropic medicines, and that rational use will work well if the variables in this study are taken into consideration in addition to other variables not in this study. This may also be supported by results in Table 4.9 which show that the study variables contribute to $30.8 \%$ of rational use. In a combined relationship Commodities (Prescribing $p<0.05)$, Facility factors $(p<0.05)$ and Complementary factors $(p<0.05)$, all had a significant influence on rational use of psychotropic medicines. The study model can thus be presented as shown below;

$$
\mathrm{Y}=0.00+0.265 X_{1}+0.065 X_{2}+0.269 X_{3}+0.242 X_{4}+e
$$

From the finding, Y-Intercept $\left(B_{0}=0.000\right)$ depicts that holding all independent variables constant, rational use will not be functional at Mathari National Referral Hospital. Further, from the findings on prescribing factors $\left(X_{l}, B_{1=} 0.265, p=0.006\right)$ implies that a unit change in prescribing factors will improve rational use of psychotropic by $26.5 \%$, the improvement is statistically significant at 5\%level of significance. In addition, the findings on patient factors, $\left(X_{2}, B_{2}=0.065, p=0.513\right)$ implies that a unit change of $\mathrm{X}_{2}$, will improve rational use by $6.5 \%$, and the improvement is not statistically significant at $p<0.05$. Further, Facility factors model, $\left(X_{3}, B_{3}=0.269, p=0.011\right)$ implies that a unit change of $\mathrm{X}_{3}$ (Facility factors) will improve rational use by $26.9 \%$, and the improvement is statistically significant at $p<0.05$. Finally, from the findings, complementary factors, $\left(X_{4}, B_{4}=0.242, p=0.009\right)$ shows that a unit change of complementary factors $X_{4}$, will improve rational use by $24.2 \%$, and the improvement is statistically significant at $p<0.05$. It therefore implies that if the results of this study are to apply; facility factors would be the place to start followed by prescribing and complementary factors. This study also reveals that the patients are not involved in decision making about their health, which could be explained by the fact that they may not be mentally sound to make decisions concerning their health, however this need to be studied further to establish the cause.

\section{SUMMARY OF FINDINGS, CONCLUSION AND RECOMMENDATIONS}

\section{Introduction}

This chapter presents the summary of the descriptive and inferential statistics. It further presents a conclusion in response to the research questions and finally presents the recommendations made in this stud and recommendation for further research.

\section{Summary of Findings}

More than half of the respondents $58(62 \%)$ were female. Majority 45(49\%) were 31-40 years, were doctors 60(65\%), held a Bachelor's Degree 47(51\%), and 53(57\%) have worked less than 5 years. About $47(50 \%)$ have prescribed and dispensed for more than 6 years, and $43(46 \%)$ of the respondents attend to more than 50 patients daily.

A bivariate correlation analysis was undertaken so as to determine the relationship between each independent variable and the dependent variable. The coefficient of correlation of prescribing practices $(r=0.397, p<0.001)$, patient factors $(r=0.289, p<0.05)$, health facility factors $(r=0.446, p<0.001)$ and complementary factors $(r=0.313, p<0.05)$ showed a positive relationship with rational use of psychotropic medicines.

A Multivariate analysis indicated that in a combined relationship (Prescribing $p<0.05)$, Facility factors $(p<0.05)$ and Complementary factors $(p<0.05)$, all had a significant influence on rational use of psychotropic medicines. Further, the findings revealed that a unit change in prescribing factors will improve rational use of psychotropic by $26.5 \%$, and the improvement was statistically significant at 5\%level of significance. In addition, a unit change of patient factors would improve rational use by $6.5 \%$, and the improvement is not statistically significant at $p<0.05$. Further, a unit change in facility factors would lead to improvement of rational use by $26.9 \%$, and the improvement was statistically significant at $p<0.05$. Finally, a unit change of complementary factors was seen to improve rational use of psychotropic medicine by $24.2 \%$, and the improvement is statistically significant at $p<0.05$. 


\section{Conclusion}

In a bivariate relationship, prescribing factors positively and significantly influence rational use of psychotropic medicines at Mathari National Referral Hospital. Often the prescribers prescribe medicine using generic name which are cheaper than branded medicine. Policies, standard treatment guidelines and the essential medicines list are not often provided to health care workers yet they are key tools in determining rational use of psychotropic medicine. The prescribers are often provided with a list of available medicines, implying stock outs of some essential medicines. Prescribers often prescribe both oral and injectable medicines without any particular preference for either.

In a bivariate relationship patient care factors positively and significantly influence rational use of psychotropic medicines in this study. Respondents agreed to consulting with patients before giving prescription, they observe privacy when dispensing medicine, and that the medicines dispensed are well labelled. In addition, they agreed to inform patients on frequency of medication and repeat to them how to take medicine and inform patients on side effects of the medicine. This is despite them handling more than 30 patients in a day.

In a bivariate relationship health facility factors positively and significantly influence rational use of psychotropic medicines in this study. This variable scored less than average for most indicators. The respondents seem to be unaware of existence of very important aspects of the supply chain that would enhance rational use of psychotropic medicines. These aspects are essential medicines list, standard treatment guidelines, consumption data to forecast drugs required, system to inform the prescriber about pharmacy stock out, enough room for storage of drugs, trainings on the rational use of psychotropic medicines, new staff induction training on the rational drug use as part of orientation process, and essential medicines being part of the basic curriculum in health training institutions /universities. However, the respondents are well aware of existence of being bin cards and monthly stock counts, which also promotes rational use of medicines.

In a bivariate relationship complementary factors positively and significantly influence rational use of psychotropic medicines in this study. Patient cultural belief, community stigma on mental health, psychosocial support, patient socio economic status and having a health insurance influence rational use of psychotropic medicines.

In a combined relationship only three independent variables (prescribing, health facility and complementary factors) influenced rational drug use. Patient care factors did not significantly influence rational drug use, though a unit increase in the patient factors would lead to a $6.5 \%$, improvement in rational use of psychotropic medicines Efforts to improve rational drug use would call for prioritized improvement of facility factors focusing on the supply chain, followed by prescribing factors, then complementary factors and finally the patient factors.

\section{RECOMMENDATIONS}

i. Prescribers and dispensers require to be provided with policies guiding rational drug use, these are the standard treatment guidelines and essential medicines list, in addition to the available medicines list. ii. The provider patient ratio requires to be reviewed as a basis of hiring more health care providers to meet the recommended WHO ratio of 1:1000 patient doctor ratio, 1:2000 patient nurse ratio and 1:1500 patient clinical officer ratio. Providers mentioned lack adequate time to explain medication to psychiatric patients or care givers and to package and label the medicine appropriately. More than $70 \%$ of the respondents attend to more than 30 psychiatric patients in a day. As per The Royal Australian and New Zealand college of Psychiatric journal a patient spends 60-75 minutes on their first visit and 30-45 minutes for ongoing treatment.

iii. Trainings on the rational use of psychotropic medicines for staff need to be undertaken frequently. In addition, new staff induction training on the rational drug use as part of orientation process need to be undertaken. Despite of training on usage of Essential medicines training in the basic curriculum in health training institutions /universities, continuous education program is necessary.

iv. NHIF the Kenyan social health insurer ought to consider covering mental health as part of the benefit package to enhance affordability of psychiatric services.

\section{RECOMMENDATIONS FOR FURTHER RESEARCH}

A research focusing on rational use of psychotropic medicine from a patient's perspective will add value to this study. This will enhance understanding of the experience they have with services, and the areas that may require improvement.

\section{REFERENCES}

[1] Abebaw, D., Haile, K., Kassaw, C., \& Belete, A. (2016). Prescribing Factors Influencing Rational use of Psychotropic Drugs for People with Severe Mental Illness in Amanuel Mental Specialized Hospital in Addis Ababa, Ethiopia . Journal of Family Medicine, 3(11), 1-7.

[2] Adeponle, A. B., Obembe, A. O., Adeyemi, S. O., \& Suleiman, G. T. (2017). Complementary Factors Influencing Rational Use of Psychotropic Medicine in Psychiatric Outpatient Practice in Northern Nigeria. African Journal of Psychiatry, 4(6), 215-219.

[3] Ajzen, I. (2012). Martin Fishbein's Legacy: The Reasoned Action Approach. The Annals of the American Academy of Political and Social Science, 640: 11-27.

[4] Ajzen, I., \& Fishbein, M. (1980). Understanding attitudes and predicting social behaviour. Englewood Cliffs, NJ: Prentice-Hal.

[5] Ali Murshid, M., \& Mohaidin, Z. (2017). Models and theories of prescribing decisions: A review and suggested a new model. Pharmacy Practice, 15(2), 990-990. https://doi.org/10.18549/PharmPract.2017.02.990

[6] Alam, M. T., Maruf, M. M., Sarkar, M., Ahmed, H. U., \& Akhter, M. (2016) Prescribing factors influencing rational use of psychotropics in the outpatient department of National Institute of Mental Health in Baghladesh . Bang Journal of Psychiatry, 29(1):10-13.

[7] Anandhasayanam, A., Arputhavanan, M., \& Subramaniam, K. (2017). patient care factors influencing rational use of Psychotropic medicines in at the Nursing Home for the Elderly, Institute of Biosciences, Universidade Estadual Paulista. Sao Paulo Medical Journal, 124(5), 123-134.

[8] Armitage, C. J., \& Conner, M. (2001). Efficacy of the theory of planned behaviour: A meta-analytic review. British Journal of Social Psychology, 40, 471-499.

[9] Ashong, S., Kretchy, I. A., Afrane, B., \& de-Graft Aikins, A. (2018). Patterns of Prescription of Psychotropic Medications and Their Adherence among Patients with Schizophrenia in Two Psychiatric Hospitals in Accra, Ghana: 
A Cross-Sectional Survey. Psychiatry Journal, 2018, 1-10. https://doi.org/10.1155/2018/9850594

[10] Basrowi, R. W., Krisnamurti, D., Wibowo, Y., \& Vandenplas, Y. (2018). Patient Care Factors Influencing Rational Use of medicine among pediatricians in Indonesia. Open Access Text, 5(4), 17-28.

[11] Barbui, C. (2015). Access and use of psychotropic medicines in low-resource settings. Epidemiology and Psychiatric Sciences, 24(3), 206-209. https://doi.org/10.1017/S2045796015000268

[12] Bezerra, I. C., de Morais, J. B., de Paula, M. L., Silva, T. M., \& Jorge, M. S. (2016). Complementary Factors Influencing Rational use of psychotropic drugs a Psychosocial Care Center (Caps) in Fortaleza, State of Ceará (CE), Brazil. SciELO Analytics, 5(3), 63-75.

[13] Bigdeli, M., Jacobs, B., Tomson, G., Laing, R., Ghaffar, A., Dujardin, B., \& Van Damme, W. (2013). Access to medicines from a health system perspective. Health Policy and Planning, 28(7), 692-704. https://doi.org/10.1093/heapol/czs108

[14] Bigdeli, M., Peters, D., \& Wagner, A. (2014). Medicines in Health Systems. https://www.healthsystemsglobal.org/twg-group/7/Medicines-in-HealthSystems/

[15] Bilal, A. I., Osman, E. D., \& Mulugeta, A. (2016). Assessment of medicines use pattern using World Health Organization's Prescribing, Patient Care and Health facility indicators in selected health facilities in eastern Ethiopia. BMC Health Services Research, 16(1). https://doi.org/10.1186/s12913-0161414-6

[16] Carl Erik Fisher et al. (2013, February). Developing mental health-care quality indicators: Toward a common framework. https://www.ncbi.nlm.nih.gov/pmc/articles/PMC3557960/

[17] Celik, E., Nazh, M., \& Clark, M. P. (2013). Factors affecting rational drug use (rdu), compliance and wastage. 19.

[18] Cushing, A., \& Metcalfe, R. (2017). Optimizing medicines management: From compliance to concordance. Ther Clinical Risk Management, 3(6), 1047-1058.

[19] Endalkachew, A., Begashaw, B., \& Hailu, W. (2017). Patient Care Factors Influencing Rational Use Of Psychotropic Drugs In Gondar University Teaching Referral Hospital. International Journal Of Pharmaceutical Sciences And Research, 9(3), 127-135.

[20] Fishbein, M. (1967). A behavior theory approach to the relations between beliefs about an object and the attitude toward the object. New York: John Wiley \& Sons.

[21] Fujita, K., Moles, R. J., \& Chen, T. F. (2018). Prescribig indicators ifluencing responsible use of medicines in Sydney, Australia. BMJ Open, 8(7), 1-21.

[22] Geffner, R., Shaw, M., \& Crowell, B. (2018). Ethical considerations in forensic evaluations in family court. In M. M. Leach, \& E. R. Welfel, Cambridge handbooks in psychology. The Cambridge handbook of applied psychological ethics (pp. 452-473). London: Cambridge University Press.

[23] Rittmannsberger, H., Meise, U., Schauflinger, K., Horvath, E., Donat, H., \& Hinterhuber, H. (1999). Polypharmacy in psychiatric treatment. Patterns of psychotropic drug use in Austrian psychiatric clinics. European Psychiatry, 14(1), 33-40.

[24] Hagger, M. S., \& Chatzisarantis, N. L. (2014). An integrated behavior change model for physical activity. Exercise and Sport Sciences Reviews, 42, 62-69.

[25] Hogerzeil, H. (1995). Promoting rational prescribing: An international perspective. British Journal of Clinical Pharmacology, 39(1), 1-6. https://doi.org/10.1111/j.1365-2125.1995.tb04402.x

[26] Hollie, M. (2017). Influence of Complementary factors on Rational Use of Psychotropic Medicine in Canada. Education Doctoral, Paper 326.

[27] Homedes, N., \& Ugalde, A. (2017). Improving the use of pharmaceuticals through patient and community level interventions. Social Science Medicine, 52(1), 99-134.

[28] Hulka, B. S., Cassel, J. C., Kupper, L. L., \& George, C. F. (2016). Communication, compliance, and concordance between physicians and patients with prescribed medications. American Journal of Public Health , 66, 847-853

[29] Kabir, M., Iliyasu, Z., Abubakar, I., \& Aliyu, M. (2014, August). Perception and beliefs about mental illness among adults in Karfi village, northern Nigeria | BMC International Health and Human Rights | Full Text. https://bmcinthealthhumrights.biomedcentral.com/articles/10.1186/1472698X-4-3

[30] Kilbourne, A. M., Beck, K., Spaeth-Rublee, B., Ramanuj, P., O’Brien, R. W., Tomoyasu, N., \& Pincus, H. A. (2018). Measuring and improving the quality of mental health care: A global perspective. World Psychiatry, 17(1), 30-38. https://doi.org/10.1002/wps.20482

[31] Kirigia, J. M., \& Sambo, L. G. (2003). Cost of mental and behavioural disorders in Kenya. Annals of General Hospital Psychiatry, 7.

[32] Kirigia, J., \& Sambo, L. (2003, July). (PDF) Cost of mental and behavioural disorders in Kenya https://www.researchgate.net/publication/10633668_Cost_of_mental_and_b ehavioural_disorders_in_Kenya

[33] Malhotra, N., Nunan, D., \& Birks, D. (2017). Marketing Research. An Applied Approach. . England: (5th ed.) Pearson Education Limited.

[34] Meyers, L. S., Gamst, G., \& Guarino, A. J. (2016). Applied Multivariate Research: Design and Interpretation. Washington, DC: Sage Publishing.

[35] MoH. (2020). Mental Health and Wellbeing: Towards Happiness and National Prosperity. Afya House, Cathedral Road, Nairobi: Ministry of Health.

[36] Maxwell, S. R. (2016, October). Rational prescribing: The principles of drug selection. https://www.ncbi.nlm.nih.gov/pmc/articles/PMC6297291/

[37] Meyer, A.-C., \& Ndetei, D. (2015, January). Appendix E: Providing Sustainable Mental Health Care in Kenya: A Demonstration Project Providing Sustainable Mental and Neurological Health Care in Ghana and Kenya: Workshop Summary | The National Academies Press. https://www.nap.edu/read/21793/chapter/11\#140

[38] Ministry of Health, K. (2015). Kenya Mental Health Policy. Ministry of health, Kenya.

[39] Management Sciences for Health (2012a), Inventory Management. http;//www.msh.org/resource centre, viewed on 22 August 2014.

[40] Management Sciences for Health (2012b), Inventory Management. http;//www.msh.org/resource centre, viewed on 22 August 2014.

[41] Management Sciences for Health (2012c), Inventory Management. http;//www.msh.org/resource centre, viewed on 22 August 2014.

[42] Nandeshkumar, A., Sathiadas, G., \& Ranganathan, S. (2020, June 5). Rational dispensing of oral dosage forms of medicines to children at a teaching hospital in Sri Lanka | BMC Health Services Research | Full Text. https://bmchealthservres.biomedcentral.com/articles/10.1186/s12913-02005246-x

[43] Notani, J. B. (2005). Modeling personal and normative influences on behavior. Journal of Consumer Research, 10(2), 24-51.

[44] Ojo, M. A., Igwilo, C. I., \& Emedoh, T. (2017). Prescribing Patterns on Perceptions of Health Care Professionals About Rational Drug use in a Specialist Hospital Clinic. Journal of Public Health in Africa, 3(7), 242-257.

[45] Olajide, A., Mansfield, M., Olubankole, O., \& Okpalauwaekwe, U. (2018). Patient Factors influencing rational use of Psychotropic Drugs in Psychiatric In-Patients in Saskatchewan, Canada. Journal Neuropsychopharmacol Mental Health, 1(4), 23-37.

[46] Olayiwola, J. A., Toluwalase, B. H., \& Tomori, B. A. (2019). Comparative Analysis of Health Facility factors Influencing Rational Use of Psychotropic Drugs in Two Tertiary Health Institutions North West Nigeria. Annals of Pharmacology and Pharmaceutics, 5(2), 1-5.

[47] Oye, G., Lasebikan, V., Ephraim-Oluwanuga, O., Olley, B., \& Kola, L. (2005). Community study of knowledge of and attitude to mental illness in Nigeria | The British Journal of Psychiatry | Cambridge Core. https://www.cambridge.org/core/journals/the-british-journal-ofpsychiatry/article/community-study-of-knowledge-of-and-attitude-tomental-illness-in-nigeria/070F7DCA68F81CA2B96B861F988E0FCC

[48] Ozawa, S., Shankar, R., Leopold, C., \& Orubu, S. (2019). Access to medicines through health

systems in low- and middle-income countries. Health Policy and Planning, 34(Supplement_3), iii1-iii3. https://doi.org/10.1093/heapol/czz119

[49] Padmanathan, P., \& Rai, D. (2016). Access and rational use of psychotropic medications in low- and middle-income countries. Epidemiology and $\begin{array}{lll}\text { Psychiatric } & \text { Sciences, } & \text { 25(1), }\end{array}$ https://doi.org/10.1017/S2045796015000803

[50] Padmanathan, P., \& Roy, S. (2001, Volume). Internet Scientific Publications. http://ispub.com/IJPHARM/1/2/6216\#

[51] RANZCP. (2017, April). Your first appointment | Your Health in Mind. https://www.yourhealthinmind.org/psychiatry-explained/your-firstappointment

This publication is licensed under Creative Commons Attribution CC BY. 
[52] Richard, O.-A., \& Akosua, A. (2016). Irrational Use of Medicines-A Summary of Key Concepts. https://www.ncbi.nlm.nih.gov/pmc/articles/PMC5419375/

[53] Sangoi, B., Naveen, K., Manjunatha, N. Mahesh, G., Basavaraju, V., \& Math, S. (2019). Health Insurance and mental illness.

[54] Sarris, J., Moylan, S., Camfield, D. A., Pase, M. P., Mischoulon, D., Berk, M., et al. (2017). Complementary Factors Influencing Rational Use of Psychotropic Drugs in USA. Evidence-Based Complementary and Alternative Medicine (eCAM), 5(3), 76-88.

[55] Saxena, S., Thornicroft, G.,Knapp, M., \& Whiteford, H. (2007). Resources for mental health: Scarcity, inequity, and inefficiency. The Lancet, 370(9590), 878-889. https://doi.org/10.1016/S0140-6736(07)61239-2

[56] Sekaran, U. (2002). Research Methods for Business: A Skill Building Approach (4 edition). Wiley.

[57] Sisay, M., Mengitsu, G., Molla, B., Amare, F., \& Gabriel, T. (2017). Evaluation of rational drug use based on World Health Organization core drug use indicators in selected public hospitals of eastern Ethiopia: A cross sectional study . BMC Health Service.

[58] Soleymani, F., Amadizar, F., Meysamie, A., \& Abdellahi, M. (2013, June). A survey on the factors influencing the pattern of medicine's use: Concerns on irrational use of drugs. https://www.ncbi.nlm.nih.gov/pmc/articles/PMC4076903/

[59] Thakkar, K. B., Jain, M. M., Billa, G., Joshi, A., \& Khobragade, A. A. (2018). Influence of Health Facility Factors on Rational Use of Psychotropic Drugs in the Psychiatry Outpatient Department of Tertiary Care Hospital in Grant Medical College \& Sir JJ Group of Hospitals , Mumbai, India. Journal of Clinical and Diagnostic Research, 7(12), 2759-2764.

[60] Titus, B., Alison, R., \& Marilyn, R. (2000, July). The success of an evidencebased rational prescribing intervention: A retrospective study | News Pharmaceutical Journal. https://www.pharmaceutical-journal.com/thesuccess-of-an-evidence-based-rational-prescribing-intervention-aretrospective-study/20002075.article?firstPass=false

[61] Wahome, D., Mwangi, E., \& Mutwiri, T. (2019, January). View of Factors Influencing Rational Drug Use in Public Hospitals among Doctors and
Pharmacists in Meru County. http://library.kemu.ac.ke/ijpp/index.php/ijpp/article/view/16/13

[62] Wenhui, M., Huang, Y., \& Chen, W. (2017). Health Facility factors influencing rational use of medicine in Hangzhou, China. PLoS ONE , 14(3), : $\mathrm{e} 0213638$.

[63] World Health Organization. (1993). How to investigate drug use in health facilities: selected drug use indicators (No. WHO/DAP/93.1 Unpublished). World Health Organization.

[64] World Health Organization. (2002). Promoting rational use of medicines: core components (No. WHO/EDM/2002.3). World Health Organization.

[65] World Health Organization. (2017a). Improving access to and appropriate use of medicines for mental disorders.

[66] World Health Organization. (2017b). Mental Health ATLAS 2017 Member State Profile.

[67] World Council of Churches. (2006). Promoting rational use of medicines. World health organization.

[68] World Health Organization (Ed.). (2010). Monitoring the building blocks of health systems: A handbook of indicators and their measurement strategies. World Health Organization.

\section{AUTHORS}

First Author - Dipti Ashish Bhavsar, B. Pharm

Second Author - Dr. Kezia Njoroge, PhD in Public Health, Msc International Health, Msc Development Economic, Bachelor of

Education (ARTS) Economics and Mathematics

Third Author - Ms. Lillian Muiruri, Department of Health

Systems Management and Medical Education, School of Medicine and Health Sciences, Kenya Methodist University 